\title{
Fontes, ornamentos e vinhetas da revista Album Imperial, impressa pela Tipografia Hennies Irmãos em 1906
}

\author{
Typefaces, ornaments and vignettes of the Album Imperial magazine, \\ printed by Tipografia Hennies Irmãos 1906
}

Thaís Fernandes Rosa, Jade Samara Piaia

tipografia, memória gráfica, cultura visual

Este artigo tem como foco a revista Album Imperial, impressa pela Tipografia Hennies Irmãos em São Paulo em 1906, e objetiva colaborar na recomposição da memória gráfica paulistana por meio do levantamento do repertório tipográfico desta revista. Os procedimentos de coleta e tratamento de dados foram aplicados a 10 edições da revista e os resultados incluem quatro famílias tipográficas, conjuntos de ornamentos e uma diversidade de vinhetas pictóricas e esquemáticas, que foram comparados com o repertório tipográfico dos Hennies levantado por pesquisas anteriores e com espécimes de tipos, revelando a origem alemã de fontes e ornamentos.

typography, graphic memory, visual culture

This article has as It's main focus the Album Imperial magazine, printed by Tipografia Hennies Irmãos in São Paulo in 1906, and aims to contribute to São Paulo's graphic memory recomposition by gathering this magazine's typography repertoire. The data collection and processing were enforced in 10 editions of the magazine and the results include four typefaces, ornament sets and a diversity of pictorial and schematic vignettes, that were compared with the Hennies' typography repertoire gathered by previous researches and types specimen, revealing the German origin of typefaces and ornaments.

\section{Introdução}

Album Imperial foi um quinzenário político e literário, impresso pela Tipografia Hennies Irmãos iniciado em 1906, publicado até 1908. Seu propósito era homenagear os membros da coroa portuguesa por meio de biografia e retratos, recordando seus feitos e a "grandeza do passado brasileiro" (Magalhães, 1906, n¹, pp. 2a capa). Circulava inicialmente na cidade de São Paulo e arredores, com anúncios comerciais de empresas na região de São Paulo e Campinas, com pontos de venda no estado de São Paulo que, ao final do primeiro ano da revista, foram ampliados para outros estados -Minas Gerais, Ceará, Rio de Janeiro, Pernambuco, Rio Grande do Sul, Amazonas, Pará e Mato Grosso (Magalhães, 1906, n. 24). A revista é entendida como uma importante fonte documental para o estudo da cultura visual e de uma memória gráfica paulistana com impacto na história do design gráfico brasileiro no início do século XX.

Anais do $10^{\circ} \mathrm{CIDI}$ e $10^{\circ} \mathrm{CONGIC}$

Kelli C.A.S. Smythe, Rafael de Castro Andrade (orgs.)

Sociedade Brasileira de Design da Informação - SBDI

Curitiba | Brasil | 2021
Proceedings of the $10^{\text {th }} \mathrm{CIDI}$ and $10^{\text {th }}$ CONGIC

Kelli C.A.S. Smythe, Rafael de Castro Andrade (orgs.)

Sociedade Brasileira de Design da Informação - SBDI Curitiba | Brazil | 2021 
O repertório da oficina tipográfica fundada em 1891 pelos imigrantes alemães Heinrich e Theodor Hennies é objeto de pesquisa de pós-doutorado em andamento no Laboratório de Pesquisa em Design Visual (LabVisual) da Faculdade de Arquitetura e Urbanismo da Universidade de São Paulo (FAUUSP) realizado pela pesquisadora Dra. Jade Samara Piaia (2019). Este estudo faz parte do projeto "Memória Gráfica Paulistana", apoiado pelo CNPq e liderado pela Dra. Priscila Lena Farias (2019), que compreende estudos sobre a formação do campo gráfico nos primeiros cem anos de atividades tipográficas em São Paulo, com um recorte temporal que vai de 1827 a 1927, período que compreende os recortes temporal e geográfico abordados.

Segundo Farias (2016) o estudo da memória gráfica envolve a reavaliação de artefatos gráficos, visando uma melhor compreensão do design enquanto elemento da cultura local. A análise da revista Album Imperial é relevante para o estudo da memória gráfica paulistana pois trata de um artefato gráfico que revela parte da vida cotidiana através de suas páginas, que veicularam anúncios comerciais e permitem o estudo das atividades comerciais e dos estilos de letras, ornamentos e vinhetas trazidos por imigrantes que contribuíram para a formação de uma estética paulistana neste período. Album Imperial pode ser entendido como uma importante fonte documental do período, revelando tendências estéticas, atividades comerciais e acontecimentos. Trata-se de um artefato relevante do ponto de vista gráfico devido ao primor na sua execução e excelente qualidade gráfica a partir de seus insumos. Os papéis especiais utilizados nas capas impressas em litografia e a qualidade do papel couchê utilizado no miolo contribuíram para que estas edições resistissem ao tempo com seus aspectos materiais preservados (figura 1).

Figura 1: Capa da revista Album Imperial (1906, ano 1, n4).

Acervo: Arquivo Público do Estado de São Paulo.

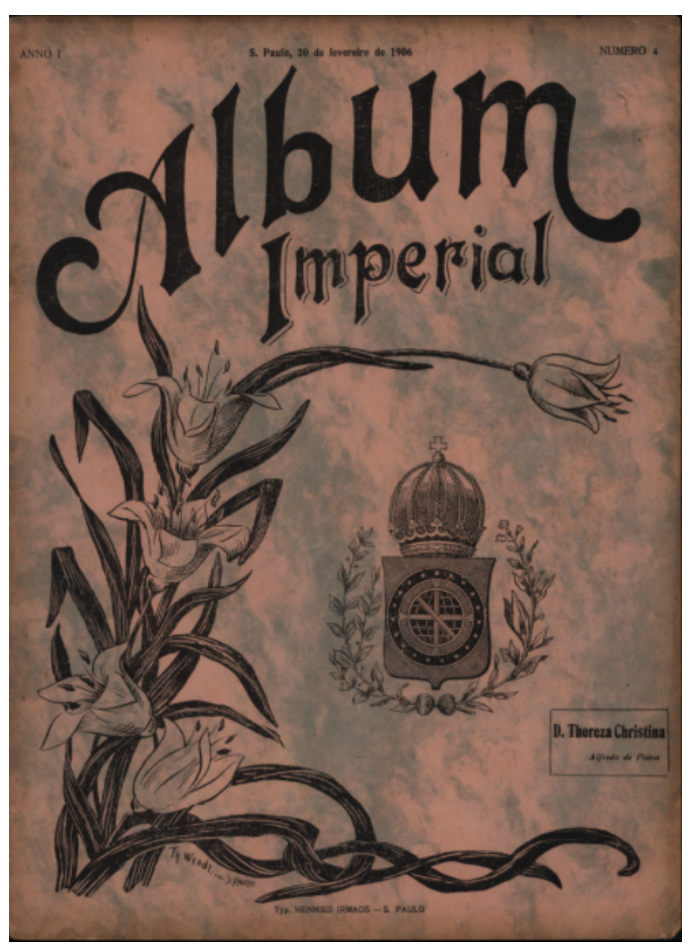




\section{Método}

Dez edições da revista Album Imperial foram consultadas, números 2, 4, 5, 6, 7, 8, 9, 10, 11 e $24^{1}$ do primeiro ano da revista, 1906, pertencentes ao Arquivo Público do Estado de São Paulo e ao Centro de Memória da Unicamp.

A plataforma online "Miro" foi utilizada no decorrer da coleta de dados, para anotações e agrupamentos das imagens de forma livre, auxiliando na organização da pesquisa. Algumas páginas foram selecionadas conforme critérios de presença de famílias tipográficas, ornamentos e vinhetas relevantes. Posteriormente, todos os dados foram planilhados.

Foram aplicados os procedimentos metodológicos observados em estudos realizados anteriormente por pesquisadores do LabVisual, como Oliveira \& Farias (2019). O material coletado foi analisado e tratado conforme os protocolos do LabVisual (Farias et. al, 2020a; 2020b), que consistem em uma série de etapas a serem seguidas no tratamento das amostras e na organização dos caracteres para upload na plataforma Tipografia Paulistana ${ }^{2}$. As imagens das páginas foram tratadas no software Adobe Photoshop (figura 2) e posteriormente separados por linhas, de texto ou de elementos de visuais, sendo os caracteres selecionados por meio da ferramenta slice e salvos para web (figura 3). Os caracteres foram organizados em pastas, segundo as famílias tipográficas encontradas, e em subpastas, segundo os corpos encontrados. Por fim, foi realizado o upload dos arquivos na plataforma.

Figura 2: Exemplo de página antes e depois do tratamento.
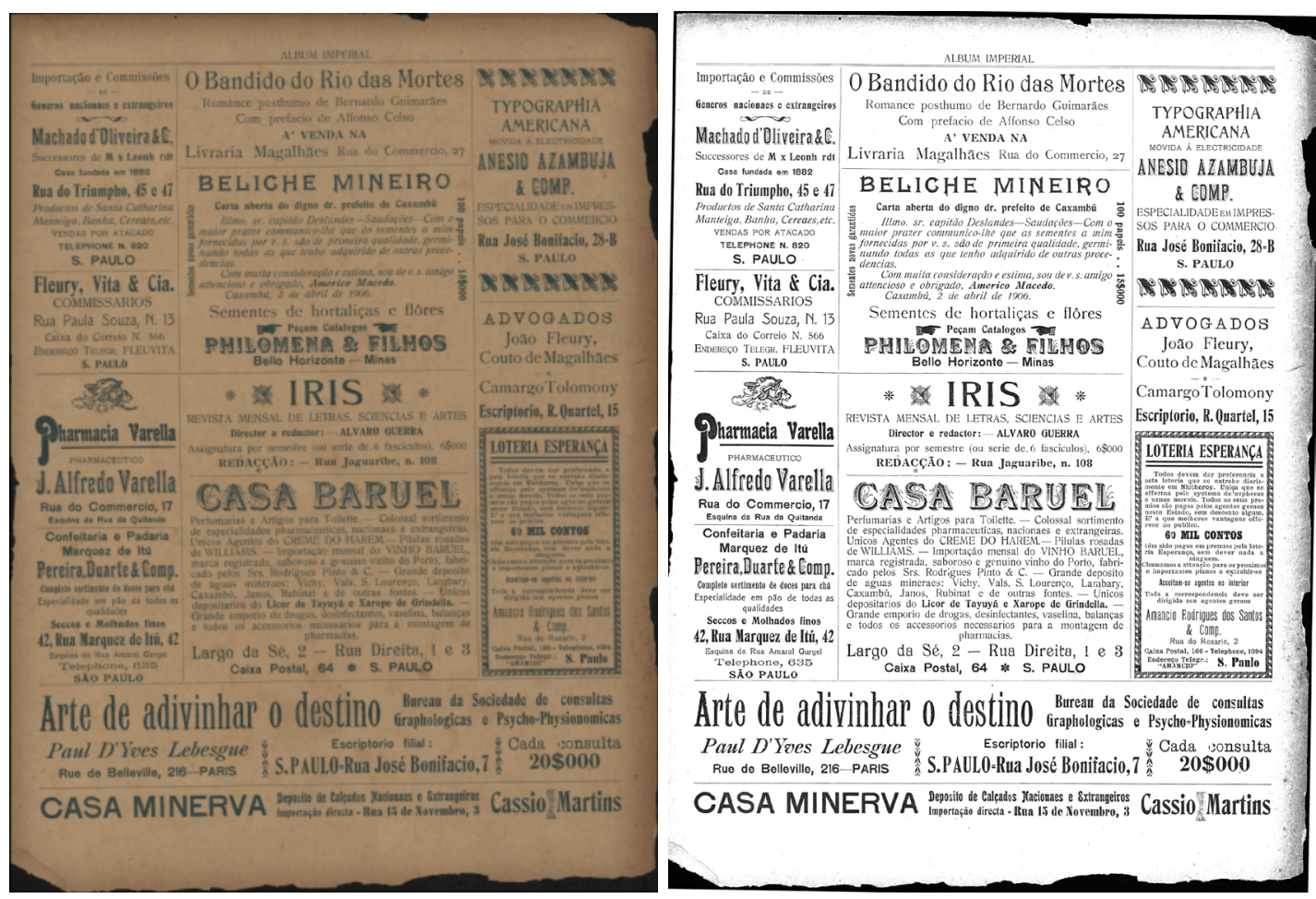

\footnotetext{
${ }^{1}$ Os originais haviam sido digitalizados ou fotografados anteriormente por Piaia (2019).

2 Disponível em https://www.fau.usp.br/tipografiapaulistana/
} 
Figura 3: Detalhe do processo de seleção dos caracteres para a geração de arquivos individuais.

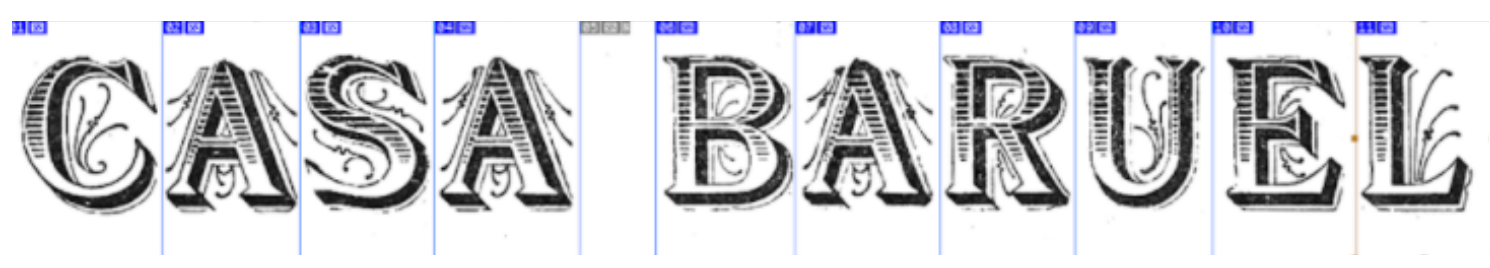

O estudo de Gastelois e Farias (2018) serviu de referência para separação dos ornamentos aplicados em molduras e organizá-los em conjuntos e também para tratamento e organização das vinhetas.

Tendo em vista a identificação das famílias tipográficas encontradas, foram utilizados para consulta e comparação um catálogo de tipos da fundidora alemã H. Berthold (s.d.), o compilado de fontes comercializadas por fundidoras alemãs organizado por Emil Wetzig (1926), bem como dados do repertório tipográfico dos Hennies previamente obtidos pela pesquisa de Piaia (2019) e disponibilizados na plataforma Tipografia Paulistana ${ }^{3}$. Esses materiais foram utilizados para comparar famílias tipográficas, ornamentos e vinhetas encontradas na revista Album Imperial e organizá-las, complementando famílias existentes ou criando novas entradas na plataforma. Os procedimentos para nomenclatura das novas famílias tipográficas seguiram o protocolo do LabVisual (Farias et. al, 2020a), que inclui o estilo da fonte e uma numeração sequencial de inserção na plataforma, incorporando entre parênteses nomenclaturas utilizadas pelos Hennies ou pela fundição, caso identificada.

\section{Resultados}

Foram encontradas quatro famílias tipográficas (tabela 1) que correspondem às famílias Alexandra ${ }^{4}$, Iniciaes Brevier ${ }^{5}$, Loreley ${ }^{6}$ e Aurora ${ }^{7}$, dois conjuntos de molduras (tabela 2 ) e doze vinhetas (tabela 3).

Tabela 1: Famílias tipográficas e exemplos dos caracteres.

\begin{tabular}{llll}
\hline $\begin{array}{l}\text { Nomenclatura } \\
\text { atribuída às fontes }\end{array}$ & Corpo & $\begin{array}{l}\text { Caracteres } \\
\text { encontrados }\end{array}$ & Exemplos dos caracteres \\
\hline $\begin{array}{l}\text { Serifada Título } \\
\text { N. } 22\end{array}$ & $24 \mathrm{pt}$ & L I H M N C \\
(Alexandra)
\end{tabular}

\footnotetext{
3 Os dados sobre a Tipografia Hennies disponibilizados na plataforma Tipografia Paulistana podem ser consultados em <https://www.fau.usp.br/tipografiapaulistana/empresa/93>.

4 Serifada Título N. ${ }^{\circ} 22$ (Alexandra) <https://www.fau.usp.br/tipografiapaulistana/familia/85>.

${ }^{5}$ Fantasia N. ${ }^{\circ} 33$ (Iniciaes Brevier) <https://www.fau.usp.br/tipografiapaulistana/familia/242>.

${ }^{6}$ Fantasia N. 25 (Loreley) <https://www.fau.usp.br/tipografiapaulistana/familia/69>.

${ }^{7}$ Fantasia N. ${ }^{\circ} 40$ (Aurora) <https://www.fau.usp.br/tipografiapaulistana/familia/333>.
} 


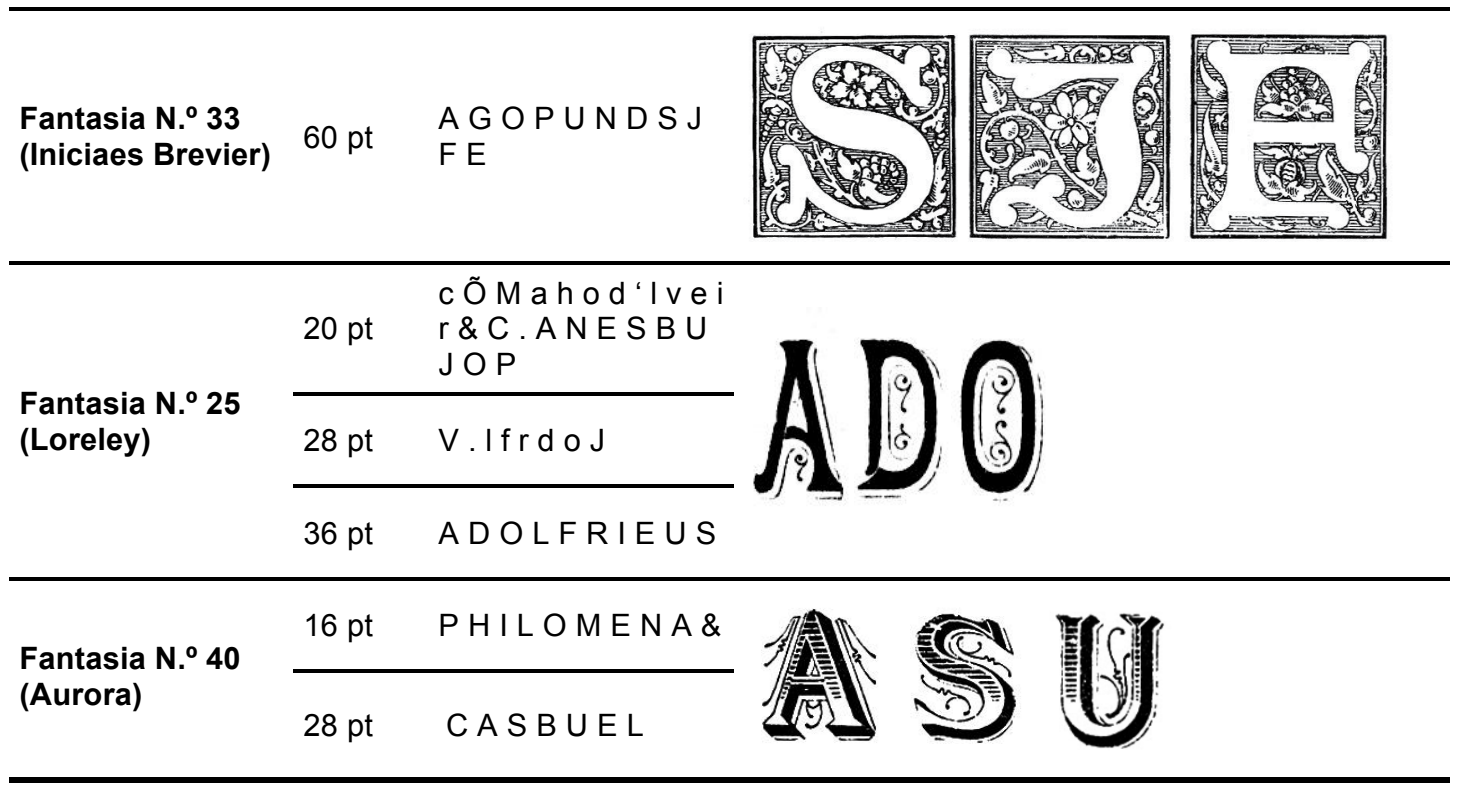

Foram obtidos caracteres do preenchimento da fonte Serifada Título N.$^{\circ} 22$ (Alexandra), que possui dois conjuntos de desenhos, um para o contorno da letra e outro para o preenchimento, possibilitando a impressão em duas cores ou o uso das versões separadas. O mesmo acontece com as capitulares floreadas da Fantasia N. ${ }^{\circ} 33$ (Iniciaes Brevier), da qual foram obtidos caracteres no corpo 60 pt da parte externa da fonte, que combina, originalmente, os caracteres de preenchimento liso com os hachurados e floreados que contornam e emolduram as letras, para impressão em duas cores. Da Fantasia N ${ }^{\circ} 25$ (Loreley) foram obtidos caracteres no corpo 20 pt, 28 pt e 36 pt, sendo que duas novas gavetas foram criadas na plataforma para receber os caracteres nos dois últimos tamanhos. A Fantasia N ${ }^{\circ} 40$ (Aurora) foi encontrada nos corpos 16 pt e 28 pt.

Tabela 2: Conjuntos de ornamentos para molduras.

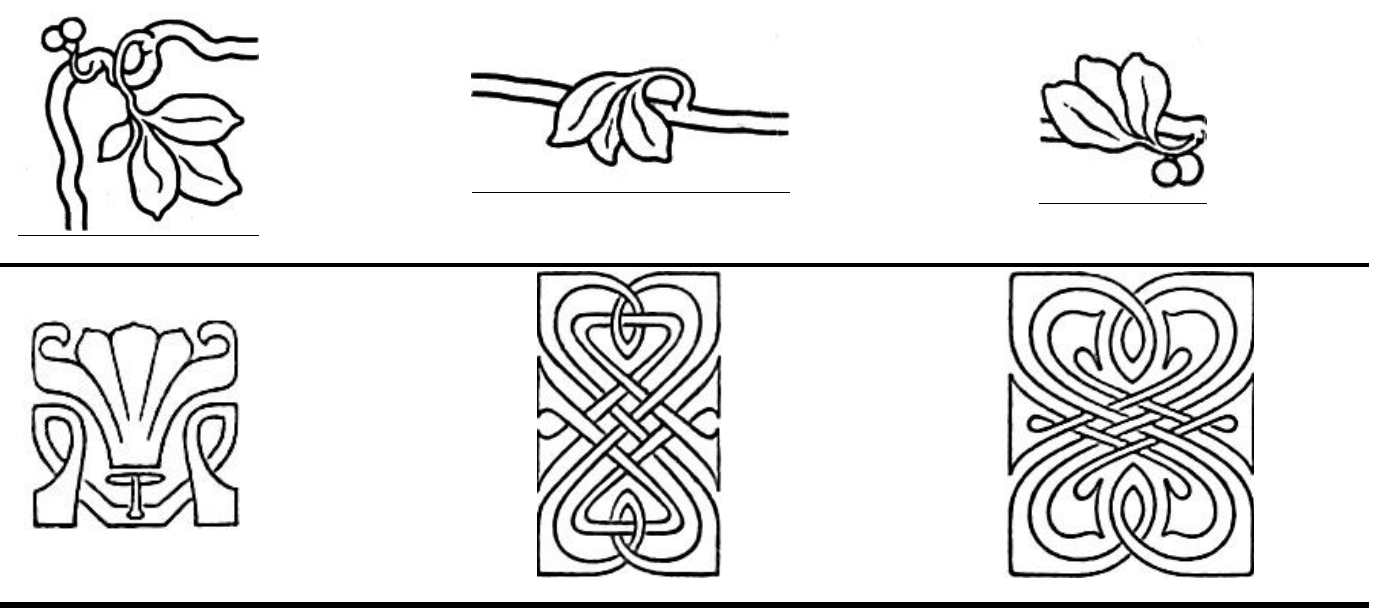


Tabela 3: Vinhetas.

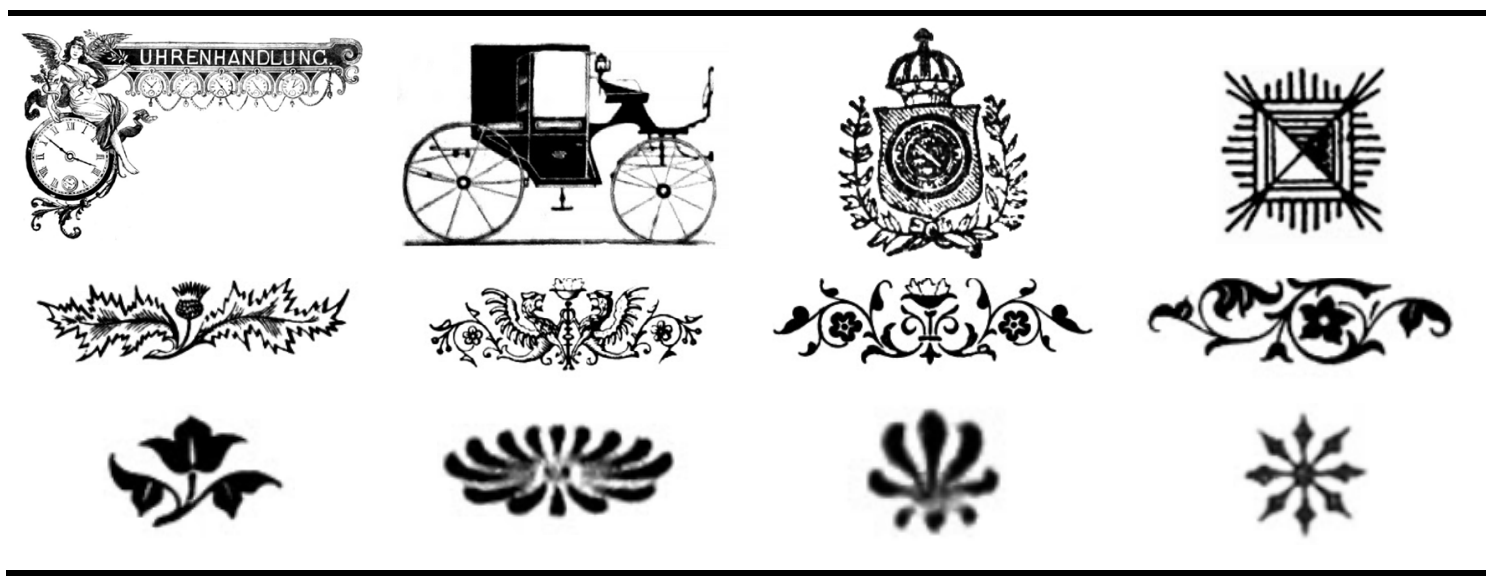

\section{Discussão}

Três famílias tipográficas foram identificadas por meio de comparações com o repertório dos Hennies (Piaia, 2019) e com o catálogo de tipos da fundidora H. Berthold (s.d.) (figura 4). A família Aurora era inédita na plataforma e foi identificada através da obra de Wetzig (1926) revelando que era comercializada pela fundidora alemã Schelter \& Giesecke desde 1888 (figura 5).

Figura 4: Detalhes das famílias Alexandra, Loreley e Brevier-Initialen no espécime da H. Berthold (s.d., pp. 80, 90g, 94g).

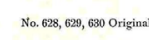

Zweifarbenschrift Alexandra

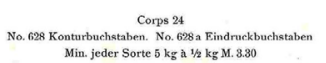

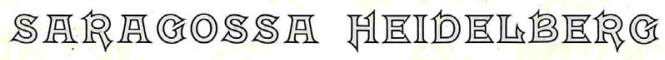

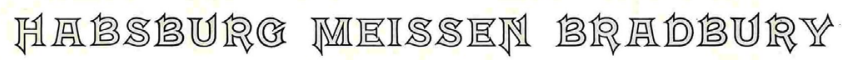

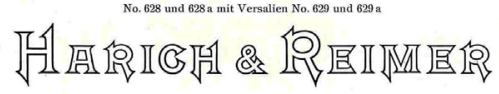
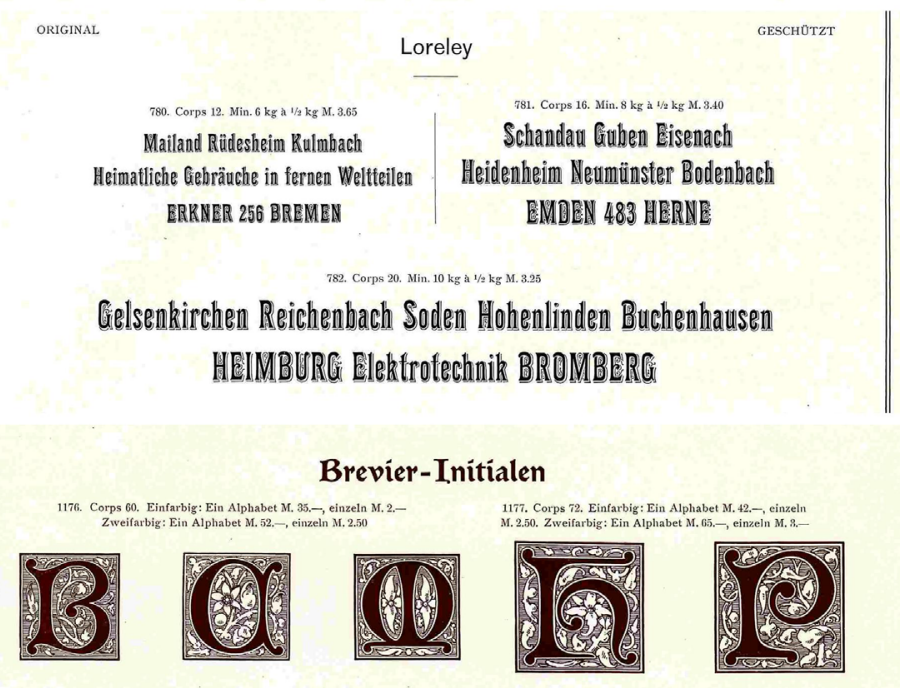
Figura 5: Amostra da fonte Aurora (Wetzig, 1926, p. 172).

Aurora Lg.-Nr. 1327 a Im Hause 1888

J. G. Schelter \& Giesecke, Leipzig

$12,16,20,28,36$

Dois conjuntos de ornamentos utilizados na composição de molduras foram coletados e tratados. Essas molduras são compostas por peças independentes que se articulam na continuidade do desenho. Uma delas possui elementos orgânicos e naturais, enquanto a outra possui desenho geométrico com arabescos. Foi possível reconhecer peças similares no espécime da fundidora alemã H. Berthold (s.d). Os conjuntos foram nomeados como "Moldura de Louros" e "Ornamento de Livro" 8 .

Figura 6: Conjuntos de ornamentos Buch-ornamente e Lorbeer-Einfassung no espécime da $\mathrm{H}$. Berthold (s.d., pp. [suplemento não numerado], 141da).
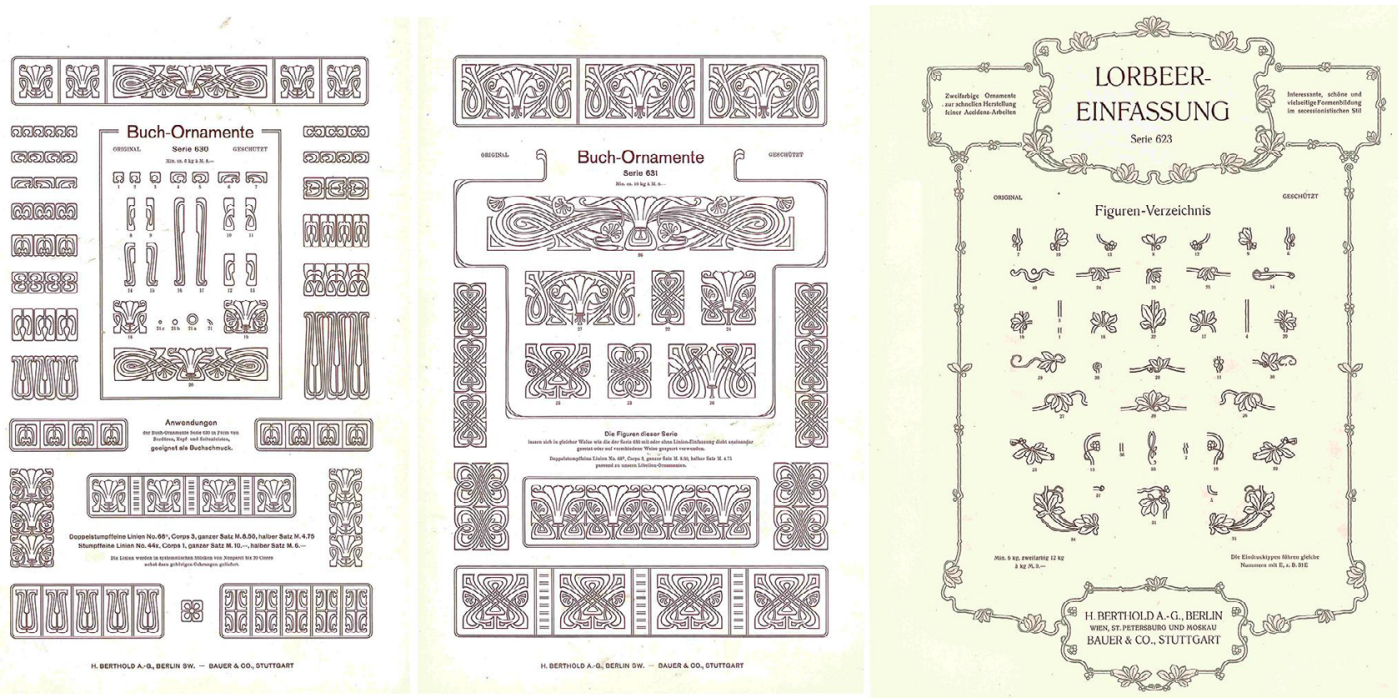

Outros resultados compreendem as vinhetas de formas geométricas, flores, objetos, automóveis e brasões. As vinhetas, que se revelaram inéditas ao serem comparadas ao repertório dos Hennies previamente coletado (Piaia, 2019), eram empregadas com diferentes funções dentro da revista, como: dividir e destacar seções de conteúdos e contextualizar anúncios comerciais.

\section{Conclusão}

A partir dos caracteres coletados foi possível observar uma presença marcante de fontes do tipo fantasia na Album Imperial, aplicadas em títulos, capitulares e anúncios. Este estudo está

${ }^{8}$ Originalmente Lorbeer-Einfassung e Buch-ornamente. 
em andamento e os caracteres estão sendo inseridos na plataforma Tipografia Paulistana, de acesso aberto e gratuito, a fim de fomentar novas pesquisas.

Este estudo contribui para a compreensão da memória gráfica paulistana ao ampliar o conhecimento acerca do repertório tipográfico disponível no início do século $\mathrm{XX}$, revelando evidências da influência alemã no repertório desta gráfica.

\section{Agradecimento}

Apoios: PIBIC, CNPq; processo n 2019/07566-6, Fundação de Amparo à Pesquisa do Estado de São Paulo (FAPESP).

\section{Referências}

Farias, P. L. (2016). Estudos sobre tipografia: letras, memória gráfica e paisagens tipográficas. Tese de livre-docência, Faculdade de Arquitetura e Urbanismo, Universidade de São Paulo.

Farias, P. L. (2019). Memória gráfica paulistana: tipografia e cultura da impressão nos primórdios da industrialização brasileira. Projeto de Pesquisa, Edital PQ CNPq. (não publicado).

Farias, P. L., et. al. (2020a). Protocolo Geral - Tipografia Paulistana. LabVisual, FAUUSP. Manuscrito não publicado.

Farias, P. L., et. al. (2020b). Protocolo de Manipulação de Imagens - Tipografia Paulistana. LabVisual, FAUUSP. Manuscrito não publicado.

Gastelois, C., \& Farias, P. L. (2018). Memória Gráfica Paulistana: ilustrações, vinhetas e ornamentos tipográficos nos almanaques comerciais de Jorge Seckler, Relatório Final de Iniciação Científica PIBIC 2017/2018, LabVisual, FAUUSP.

H. Berthold, Messinglinienfabrik und Schriftgiesserei A. G. (sem data). Schriften und Ornamente: Messing-Universalblatt und Vignetten. Spezial-Kataloge. Berlin. Acervo: Família Hennies.

Magalhães, C. (1906). Revista Album Imperial, n¹. São Paulo: Hennies Irmãos. Acervo: Arquivo Público do Estado de São Paulo.

Magalhães, C. (1906). Revista Album Imperial, n²4. São Paulo: Hennies Irmãos. Acervo: Centro de Memória Unicamp.

Oliveira, V. M., \& Farias, P. L. (2019). O repertório de tipos da Typographia Imparcial de Marques \& Irmão entre 1857 e 1862. InfoDesign - Revista Brasileira de Design da Informação, 16(3), 467-476. https://doi.org/10.51358/id.v16i3.770

Piaia, J. S. (2019). O repertório tipográfico da Tipografia Hennies: contribuições para a memória gráfica paulistana. Pesquisa de pós-doutorado (manuscrito não publicado) apoiada pela FAPESP, FAUUSP, São Paulo. Disponível em https://bv.fapesp.br/pt/pesquisador/705449/jade-samara-piaia/

Wetzig, E. (1926). Handbuch der Schriftarten. Leipzig, Albrecht Seemann Verlag. 


\section{Sobre as autoras}

Thais Fernandes Rosa, bolsista de Iniciação Científica, FAUUSP, Brasil. <thaesrosa@usp.br> Jade Samara Piaia, Pesquisadora de Pós-doutorado, FAUUSP, Brasil. <jadepiaia@usp.br> 